\title{
Effect of Consumption of Cocoa-Derived Products on Uric Acid Crystallization in Urine of Healthy Volunteers
}

\author{
Antonia Costa-Bauza, Felix Grases *, Paula Calvó, Adrian Rodriguez and Rafael M. Prieto \\ Laboratory of Renal Lithiasis Research, University Institute of Health Sciences Research (IUNICS-IdISBa), \\ University of Balearic Islands, Ctra. Valldemossa km 7.5, 07122 Palma de Mallorca, Spain; \\ antonia.costa@uib.es (A.C.-B.); pauletaa.95@hotmail.com (P.C.); adrian.rodriguez@uib.es (A.R.); \\ rafelm.prieto@uib.es (R.M.P.) \\ * Correspondence: fgrases@uib.es
}

Received: 5 September 2018; Accepted: 10 October 2018; Published: 16 October 2018

\begin{abstract}
The purpose of this study was to determine the effects of consumption of different cocoa-derived products on uric acid crystallization in urine of 20 healthy volunteers. Participants were requested to select the specific diet that they wished to follow during the $12 \mathrm{~h}$ prior to collection of urine. The only restriction was that the diet could not include any product with cocoa, coffee, or caffeine. On the first day, each volunteer followed their selected diet, and an overnight $12 \mathrm{~h}$ urine sample was collected as the baseline urine. After seven days on an unrestricted diet, each volunteer repeated the same diet with $20 \mathrm{~g}$ of milk chocolate, chocolate powder, or dark chocolate during breakfast and another $20 \mathrm{~g}$ during dinner. Overnight $12 \mathrm{~h}$ urine samples were then collected. Urine volume, $\mathrm{pH}$, oxalate, creatinine, uric acid, theobromine, and a uric acid crystallization test were determined for each sample. The results for all 20 patients show that uric acid crystallization was significantly lower following the consumption of chocolate powder or dark chocolate relative to baseline or following the consumption of milk chocolate. The results indicated that increased concentrations of urinary theobromine reduced the risk of uric acid crystallization.
\end{abstract}

Keywords: uric acid; urolithiasis; cocoa; theobromine; therapy

\section{Introduction}

Renal lithiasis currently has a prevalence of about $10 \%$ worldwide [1], and the estimated prevalence will be about $30 \%$ by 2050 [2]. Renal calculi are composed of different substances, and uric acid is present in 7 to $14 \%$ of all calculi [3-6]. Uric acid stones mainly affect males, have a high rate of recurrence, and are associated with other pathologies, such as diabetes and obesity [7-9]. In general, 50 to $70 \%$ of patients with renal lithiasis who do not receive treatment or do not modify their diets will develop new renal calculi within five years $[10,11]$, while very variable recurrence rates (5 to $100 \%$ per year) have been observed for patients with calcium kidney stones who modify their diet or follow a pharmacological treatment [12].

The main cause of uric acid crystallization is the supersaturation of urine [13], although there are other important factors. For example, urinary $\mathrm{pH}$ may be more important than hyperuricosuria, because a pH below 5.5 markedly decreases the solubility of uric acid. In fact, patients with uric acid stones have lower urinary $\mathrm{pH}$ than healthy individuals [14,15]. On the other hand, many healthy individuals have urinary $\mathrm{pH}$ values below 5.5 and high uric acid concentration, but no uric acid stones. Consequently, a low $\mathrm{pH}$ contributes to the formation of uric acid kidney stones, but there are other factors.

The dietary measures and pharmacological treatments currently used to treat uric acid stones have not changed very much in the last 25 years. These recommendations mainly consist of 
reduced consumption of purine-containing foods, increased fluid intake, urinary alkalization, and administration of allopurinol or febuxostat, but their use should be limited to patients with high urinary uric acid levels and calcium stones or for patients in which alkalinization is not successful [16-18]. None of the strategies for treatment or prevention of uric lithiasis employ crystallization inhibitors, and there are no medically available inhibitors of uric acid crystallization.

Recent research indicated that theobromine can inhibit uric acid crystallization, suggesting it may be useful for the prevention of uric acid urolithiasis [19]. Theobromine is, thus, the first natural product known to inhibit the crystallization of uric acid, and has potential for use in the treatment of renal stone formers. Moreover, theobromine is excreted in urine at concentrations similar to those needed to prevent uric acid crystallization $[20,21]$.

Theobromine is a dimethylxanthine that is abundant in cocoa and cocoa-derived products, such as chocolate [22]. Clinical studies indicated that its half-life in serum is 6.1 to $10 \mathrm{~h}$, and that 16 to $18 \%$ of a single dose of $10 \mathrm{mg} / \mathrm{kg}$ is excreted unchanged after $48 \mathrm{~h}[23,24]$. Consumption of caffeine can also lead to excretion of theobromine, and about $11 \%$ of an oral dose of caffeine is excreted as theobromine due to metabolism in the liver [25].

In this paper, we developed a method to assess the urinary uric acid crystallization risk (UAC test), and then used this test to determine the effects of consumption of different cocoa-derived products on the capacity of the urine of healthy subjects to form uric acid crystals.

\section{Materials and Methods}

\subsection{Chemicals and Reagents}

Uric acid, theobromine, and acetonitrile, which were all high performance liquid chromatography (HPLC) gradient grade, were from Sigma (St. Louis, MO, USA). All solutions were prepared in ultra-pure water from a Milli-Q water purifier. Analytical and guard columns were from Phenomenex (Torrance, CA, USA).

\subsection{Participants}

Twenty healthy adult volunteers ( 11 males and 9 females, mean age: 37 years, age range: 22 to 65 years) from Mallorca, Spain, participated in the study. None of the participants had chronic diseases or were receiving pharmacological treatments, and none were allergic to theobromine or cocoa/chocolate. All subjects provided written informed consent. The nutritional intervention protocol (IB 3475/17 PI) was approved by the local Ethics Investigation Committee of the Balearic Islands, Spain. The authors (A.C.-B., F.G., A.R., R.M.P.) declare that they are the inventors of a patent based on theobromine capacity as crystallization inhibitor of the formation of crystals of uric acid in urine (International Application No.: PCT/ES2015/070301).

\subsection{Nutritional Intervention and Urine Collection}

Participants were requested to select the specific diet that they wished to follow during the $12 \mathrm{~h}$ prior to collection of every urine, with the aim of reducing the influence of diet on the urinary composition as much as possible. The only restriction was that the diet could not include any product with cocoa, coffee, or caffeine.

On the first day, each volunteer followed his or her selected diet, and an overnight $12 \mathrm{~h}$ urine sample (starting at 8:00 p.m. and ending with the first morning urine at 8:00 a.m.), was collected and designated as the baseline urine (B).

After 7 days on an unrestricted diet, each volunteer repeated the same diet with $20 \mathrm{~g}$ of milk chocolate, chocolate powder, or dark chocolate during breakfast and another $20 \mathrm{~g}$ during dinner. Overnight $12 \mathrm{~h}$ urine samples were collected after 7 days of each cocoa product consumption. These cocoa-derived products were all from the same commercial source. 


\subsection{Sample Analysis}

Urine volume, $\mathrm{pH}$, oxalate, creatinine, uric acid, theobromine, and the UAC test were determined for each sample. Urinary $\mathrm{pH}$ was measured with a Crison $\mathrm{pH} 25$, oxalate was determined enzymatically by the oxalate oxidase/peroxidase method (LTS, Milano, Italy), creatinine by the kinetic Jaffe method, uric acid by the uricase method, and theobromine by HPLC, as described previously [20]. The HPLC system (Waters, Milford, MA, USA) had an automatic injector (WISP700), a pump system (600), a photodiode array detector (PDA 996), and Empower software. The analytical column was a 5- $\mathrm{mm}$ reversed-phase column (Gemini C18 $110 \mathrm{~A} ; 150 \times 4.6 \mathrm{~mm}$ ) protected with a Phenomenex security C18 guard cartridge $(4 \times 3.0 \mathrm{~mm})$. Mobile phase A was ammonium acetate $(20 \mathrm{mmol} / \mathrm{L}, \mathrm{pH} 7.5)$ : acetonitrile $(98: 2, \mathrm{vol} / \mathrm{vol})$ and mobile phase B was pure acetonitrile. The system was programmed in steps of $0-18 \%$ B over $15 \mathrm{~min}$, maintenance of $18 \%$ B for $3 \mathrm{~min}$, return to the initial conditions over $1 \mathrm{~min}$, and equilibration for $4 \mathrm{~min}$. The mobile phase was continuously sparged with nitrogen. The injection volume was $10 \mu \mathrm{L}$, and theobromine was eluted at a flow rate of $1 \mathrm{~mL} / \mathrm{min}$. Peak areas were measured at $273 \mathrm{~nm}$.

\subsection{UAC Test}

The UAC test (Figure 1) was performed in polystyrene non-treated 12-well plates (Corning, NY, USA). First, $5 \mathrm{~mL}$ of each urine sample was added to each of 6 wells. The first well had no additions, but hydrochloric acid and/or uric acid was added to the other wells to promote the crystallization of uric acid. The 6 wells were kept at room temperature for $24 \mathrm{~h}$, after which the urine was removed. The UAC test of each sample was determined by the number of wells in which there were uric acid crystals, ranging from 0 to 6 ).

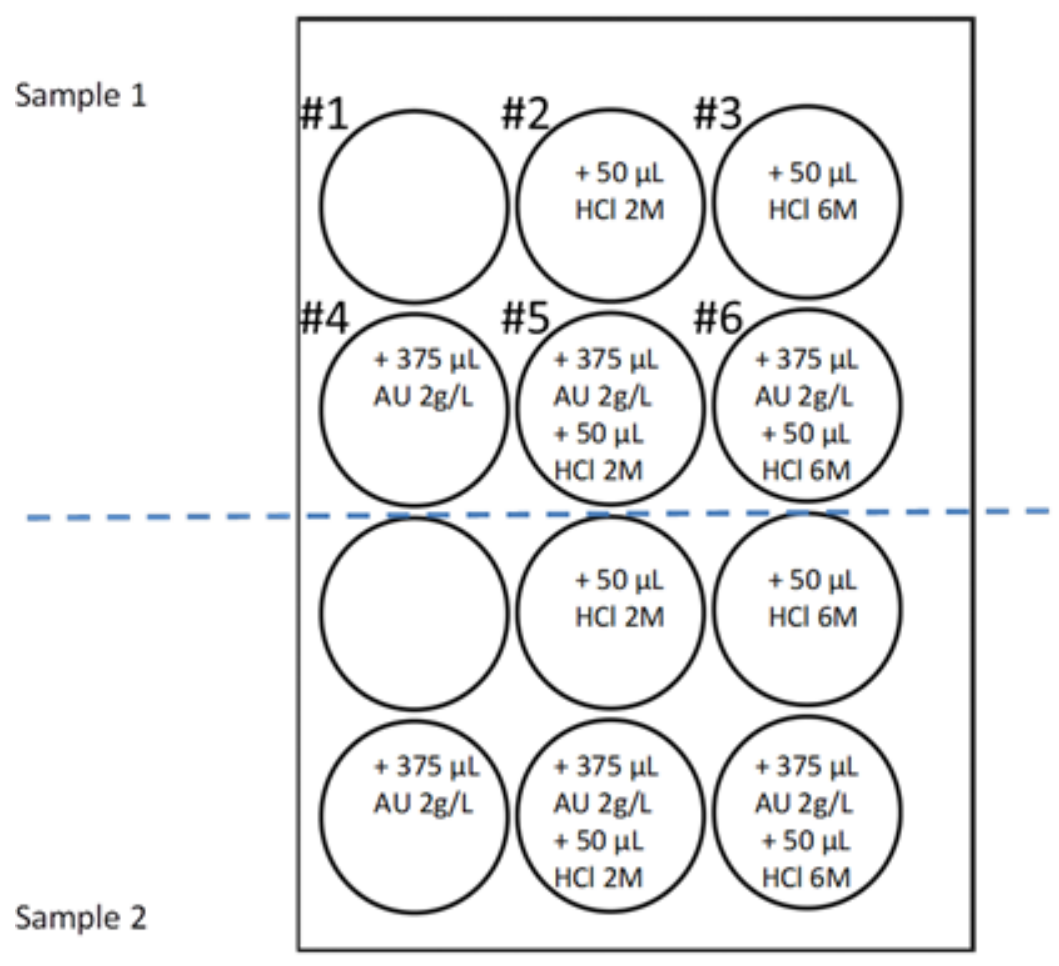

Figure 1. Uric acid crystallization (UAC) test. Six wells of a 12-well plate were used for each sample of urine, with each well containing $5 \mathrm{~mL}$ of urine and different amounts of HCL and uric acid. Well \#1 had urine alone, well \#2 had urine and $50 \mu \mathrm{L}$ of $2 \mathrm{M} \mathrm{HCl}\left(0.1 \mathrm{mmoL} \mathrm{H}^{+}\right)$, well \#3 had urine and $50 \mu \mathrm{L}$ of $6 \mathrm{M} \mathrm{HCl}\left(0.3 \mathrm{mmol} \mathrm{H}{ }^{+}\right)$, well \#4 had urine and $750 \mu \mathrm{g}$ uric acid $(375 \mu \mathrm{L}$ of $2 \mathrm{~g} / \mathrm{L}$ solution), well \#5 had urine, $50 \mu \mathrm{L}$ of $2 \mathrm{M} \mathrm{HCl}$ and $750 \mu \mathrm{g}$ uric acid, and well \#6 had urine, $50 \mathrm{~mL} 6 \mathrm{M} \mathrm{HCl}$ and $750 \mu \mathrm{g}$ uric acid. Uric acid (AU). + means addition of the specified volume of the solution. 


\subsection{Statistical Analysis}

The normality of the data was assessed by plotting histograms and using the Shapiro-Wilk test. For continuous variables, all results are expressed as means \pm standard deviations or as medians and percentages. A repeated measures ANOVA, with a Bonferroni post hoc test for normally distributed variables, was used. Alternatively, the non-parametric Wilcoxon signed-rank test was used to assess differences between groups. A $p$ value below 0.05 was considered statistically significant. IBM SPSS Statistics version $22^{\circledR}$ for Windows (SPSS Inc., Chicago, IL, USA) was used for statistical analyses.

\section{Results}

Figure 2A shows the urinary concentration of theobromine and Figure $2 \mathrm{~B}$ shows the total theobromine excretion in $12 \mathrm{~h}$ in each of the 20 volunteers. Pooling these data (Figure 2C,D) indicated that the mean urinary concentration of theobromine and total theobromine excretion in $12 \mathrm{~h}$ was significantly greater after consumption of each cocoa-derived product than at baseline $(p<0.05$ for each comparison).
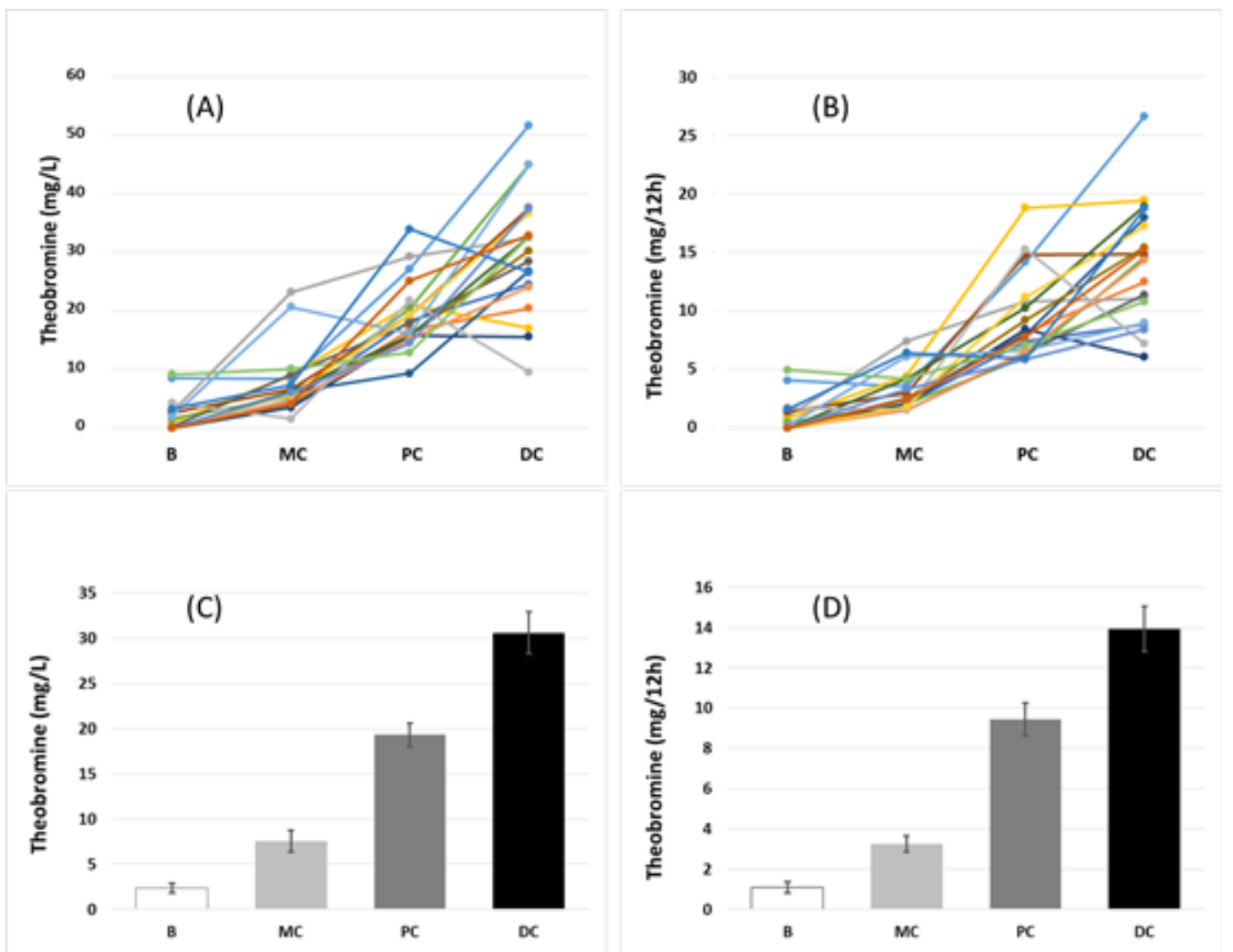

Figure 2. Effect of the consumption of different cocoa products on urinary theobromine concentration (A) and total theobromine excretion in $12 \mathrm{~h}$ (B) in each of the 20 volunteers (each colored line corresponds to one of the volunteers), and mean concentration (C) and total excretion in $12 \mathrm{~h}$ (D) among all 20 volunteers. An ANOVA repeated measures test indicated significant differences among the four groups in concentration and excretion $(p<0.05)$. B: basal, MC: milk chocolate, PC: chocolate powder, and DC: dark chocolate.

Table 1 shows that the different urine samples had no significant differences in $\mathrm{pH}$ or uric acid. However, the urinary oxalate concentration was significantly greater following consumption of dark chocolate than at baseline, or following consumption of chocolate powder $(p<0.05$ for each comparison). 
Table 1. Individual volunteer $(n=20)$ data, mean, median and standard deviation (SD) of urinary parameters ( $\mathrm{pH}$, uric acid, oxalate, theobromine, UAC test and uric acid relative supersaturation (RSS) [26]) for basal conditions and under cocoa derived products nutritional intervention.

\begin{tabular}{|c|c|c|c|c|c|c|c|c|c|c|c|c|}
\hline \multirow{2}{*}{$\begin{array}{c}\text { Volunteer } \\
1\end{array}$} & \multicolumn{4}{|c|}{$\mathrm{pH}$} & \multicolumn{4}{|c|}{ Uric Acid (mg/L) } & \multicolumn{4}{|c|}{ Oxalate $(\mathrm{mg} / \mathrm{L})$} \\
\hline & B & $\mathrm{MC}$ & PC & $\mathrm{DC}$ & B & $\mathrm{MC}$ & PC & DC & $\mathrm{B}$ & $\mathrm{MC}$ & PC & DC \\
\hline 2 & 5.85 & 6.05 & 5.68 & 6.39 & 404 & 460 & 461 & 393 & 16 & 17 & 15 & 16 \\
\hline 3 & 6.44 & 6.03 & 5.54 & 6.33 & 346 & 623 & 478 & 555 & 11 & 22 & 10 & 18 \\
\hline 4 & 7.05 & 5.73 & 6.58 & 5.53 & 207 & 142 & 210 & 336 & 37 & 39 & 40 & 34 \\
\hline 5 & 5.00 & 6.25 & 6.58 & 5.72 & 273 & 679 & 398 & 367 & 16 & 25 & 13 & 16 \\
\hline 6 & 4.90 & 5.40 & 5.04 & 5.15 & 453 & 396 & 391 & 525 & 20 & 33 & 19 & 39 \\
\hline 7 & 5.02 & 5.60 & 5.40 & 5.74 & 562 & 709 & 571 & 857 & 37 & 34 & 38 & 58 \\
\hline 8 & 5.35 & 5.22 & 5.39 & 5.10 & 393 & 549 & 156 & 270 & 15 & 29 & 8 & 27 \\
\hline 9 & 5.65 & 5.43 & 6.35 & 5.81 & 326 & 608 & 276 & 516 & 15 & 25 & 10 & 50 \\
\hline 10 & 5.84 & 5.56 & 5.66 & 5.60 & 537 & 558 & 725 & 489 & 36 & 9 & 45 & 26 \\
\hline 11 & 5.54 & 5.72 & 6.35 & 6.60 & 404 & 400 & 317 & 539 & 16 & 39 & 12 & 29 \\
\hline 12 & 5.66 & 5.92 & 5.68 & 5.44 & 469 & 688 & 528 & 405 & 24 & 12 & 28 & 44 \\
\hline 13 & 6.20 & 5.62 & 5.86 & 5.89 & 847 & 281 & 303 & 561 & 31 & 36 & 15 & 23 \\
\hline 14 & 5.33 & 5.32 & 5.04 & 5.53 & 847 & 951 & 389 & 891 & 23 & 24 & 22 & 40 \\
\hline 15 & 5.29 & 5.23 & 5.15 & 5.20 & 728 & 757 & 594 & 610 & 27 & 42 & 31 & 25 \\
\hline 16 & 5.62 & 5.49 & 6.07 & 5.86 & 313 & 113 & 277 & 230 & 23 & 6 & 14 & 18 \\
\hline 17 & 6.15 & 5.33 & 6.23 & 7.03 & 316 & 813 & 283 & 496 & 16 & 24 & 16 & 27 \\
\hline 18 & 5.42 & 5.64 & 6.22 & 5.50 & 392 & 285 & 139 & 508 & 22 & 10 & 10 & 36 \\
\hline 19 & 6.40 & 6.58 & 6.96 & 5.64 & 286 & 720 & 311 & 706 & 24 & 28 & 27 & 42 \\
\hline 20 & 6.06 & 5.40 & 5.20 & 5.53 & 188 & 178 & 252 & 169 & 11 & 10 & 14 & 13 \\
\hline mean & 5.69 & 5.65 & 5.80 & 5.72 & 425 & 507 & 387 & 483 & 22 & 24 & 21 & $32^{*}$ \\
\hline median & 5.64 & 5.58 & 5.68 & 5.59 & 393 & 554 & 353 & 502 & 21 & 25 & 16 & 30 \\
\hline SD & 0.56 & 0.36 & 0.59 & 0.48 & 195 & 244 & 167 & 191 & 8 & 11 & 11 & 12 \\
\hline Volunteer & \multicolumn{4}{|c|}{ Theobromine (mg/L) } & \multicolumn{4}{|c|}{ UAC test } & \multicolumn{4}{|c|}{ Uric acid RSS } \\
\hline 1 & B & $\mathrm{MC}$ & PC & DC & B & $\mathrm{MC}$ & PC & DC & B & $\mathrm{MC}$ & PC & DC \\
\hline 2 & 8.5 & 8.5 & 27.2 & 51.7 & 1 & 2 & 0 & 0 & -0.37 & -0.65 & 0.15 & -1.52 \\
\hline 3 & 0.0 & 4.2 & 16.8 & 20.5 & 2 & 4 & 2 & 3 & -1.76 & -0.28 & 0.51 & -1.02 \\
\hline 4 & 2.7 & 23.2 & 29.3 & 32.5 & 1 & 1 & 1 & 3 & -3.47 & -1.25 & 2.58 & 0.14 \\
\hline 5 & 0.9 & 9.0 & 21.0 & 17.1 & 4 & 2 & 0 & 1 & 1.20 & -0.64 & -1.88 & -0.19 \\
\hline 6 & 0.0 & 4.8 & 18.3 & 24.6 & 1 & 4 & 0 & 0 & 2.01 & 0.63 & 1.49 & 1.54 \\
\hline 7 & 1.6 & 5.3 & 20.5 & 45.0 & 3 & 4 & 0 & 1 & 1.94 & 0.81 & 1.03 & 0.70 \\
\hline 8 & 0.0 & 6.2 & 9.4 & 26.8 & 2 & 2 & 0 & 1 & 0.74 & 1.42 & -0.37 & 0.93 \\
\hline 9 & 2.6 & 6.7 & 19.2 & 37.6 & 4 & 3 & 0 & 0 & -0.16 & 1.03 & -1.83 & -0.01 \\
\hline 10 & 0.2 & 9.1 & 17.9 & 28.5 & 2 & 2 & 3 & 1 & -0.03 & 0.63 & 0.69 & 0.40 \\
\hline 11 & 0.0 & 4.2 & 15.9 & 30.3 & 3 & 2 & 1 & 0 & 0.32 & -0.09 & -1.68 & -1.58 \\
\hline 12 & 0.0 & 3.5 & 15.8 & 15.6 & 1 & 4 & 0 & 0 & 0.22 & 0.07 & 0.30 & 0.56 \\
\hline 13 & 0.0 & 6.3 & 15.8 & 32.7 & 2 & 2 & 1 & 2 & -0.29 & -0.26 & -0.71 & -0.09 \\
\hline 14 & 2.0 & 20.7 & 16.2 & 45.0 & 6 & 6 & 2 & 4 & 1.63 & 1.78 & 1.48 & 1.22 \\
\hline 15 & 0.0 & 4.6 & 15.2 & 24.1 & 6 & 6 & 6 & 4 & 1.56 & 1.75 & 1.67 & 1.58 \\
\hline 16 & 4.3 & 1.6 & 21.8 & 9.6 & 2 & 2 & 2 & 1 & -0.14 & -0.96 & -1.25 & -1.01 \\
\hline 17 & 0.0 & 5.7 & 19.3 & 36.7 & 4 & 4 & 2 & 6 & -1.27 & 1.58 & -1.56 & -2.48 \\
\hline 18 & 0.0 & 6.1 & 15.4 & 37.5 & 2 & 2 & 0 & 0 & 0.57 & -0.29 & -2.32 & 0.67 \\
\hline 19 & 9.2 & 10.1 & 12.9 & 32.7 & 2 & 2 & 1 & 1 & -1.89 & -1.23 & -2.86 & 0.71 \\
\hline 20 & 3.3 & 7.3 & 34.0 & 26.6 & 1 & 2 & 0 & 1 & -1.66 & -0.25 & 0.61 & -0.61 \\
\hline mean & 2.3 & 7.6 & 19.3 & 30.6 & 2.6 & 3.0 & 1.3 & 1.6 & -0.01 & 0.18 & -0.35 & -0.00 \\
\hline median & 1.0 & 6.2 & 18.1 & 31.4 & 2.0 & 2.0 & 1.0 & 1.0 & 0.09 & -0.15 & -0.11 & 0.08 \\
\hline SD & 2.4 & 5.4 & 5.9 & 10.3 & 1.7 & 1.3 & 1.7 & 1.7 & 1.44 & 0.97 & 1.55 & 1.09 \\
\hline
\end{tabular}

${ }^{*} p<0.05$ DC vs. B and PC. B: Basal conditions, MC: Milk chocolate consumption, PC: Cocoa powder consumption, DC: Dark chocolate consumption.

The reproducibility of the UAC test has been studied, using the urine of two different healthy volunteers, repeating the test five times for each urine. As can be seen in Table 2, an absolute reproducibility of the UAC test results was observed, which justifies the validity of the test. 
Table 2. Uric acid concentration, $\mathrm{pH}$ and UAC test reproducibility $(n=5)$ for two different urine samples.

\begin{tabular}{ccccc}
\hline Urine Sample & & \multicolumn{2}{c}{ UAC Test } \\
\hline & Uric acid $(\mathrm{mg} / \mathrm{L})$ & $\mathrm{pH}$ & mean & $\mathrm{SD}$ \\
Sample 1 & 608 & 5.76 & 4 & 0 \\
Sample 2 & 210 & 5.69 & 2 & 0 \\
\hline
\end{tabular}

SD: Standard deviation of 5 replicates.

We used the UAC test to examine urine samples at baseline and after consumption of the different cocoa-derived products. Figure 3 shows the results of one representative individual. This individual had markedly reduced crystallization following the consumption of chocolate powder (PC), and dark chocolate (DC). The results for all 20 patients show that the UAC was significantly lower following the consumption of chocolate powder (PC) or dark chocolate (DC) relative to baseline (B), or following consumption of milk chocolate (MC). In Figure $4, p<0.05$ for each comparison).
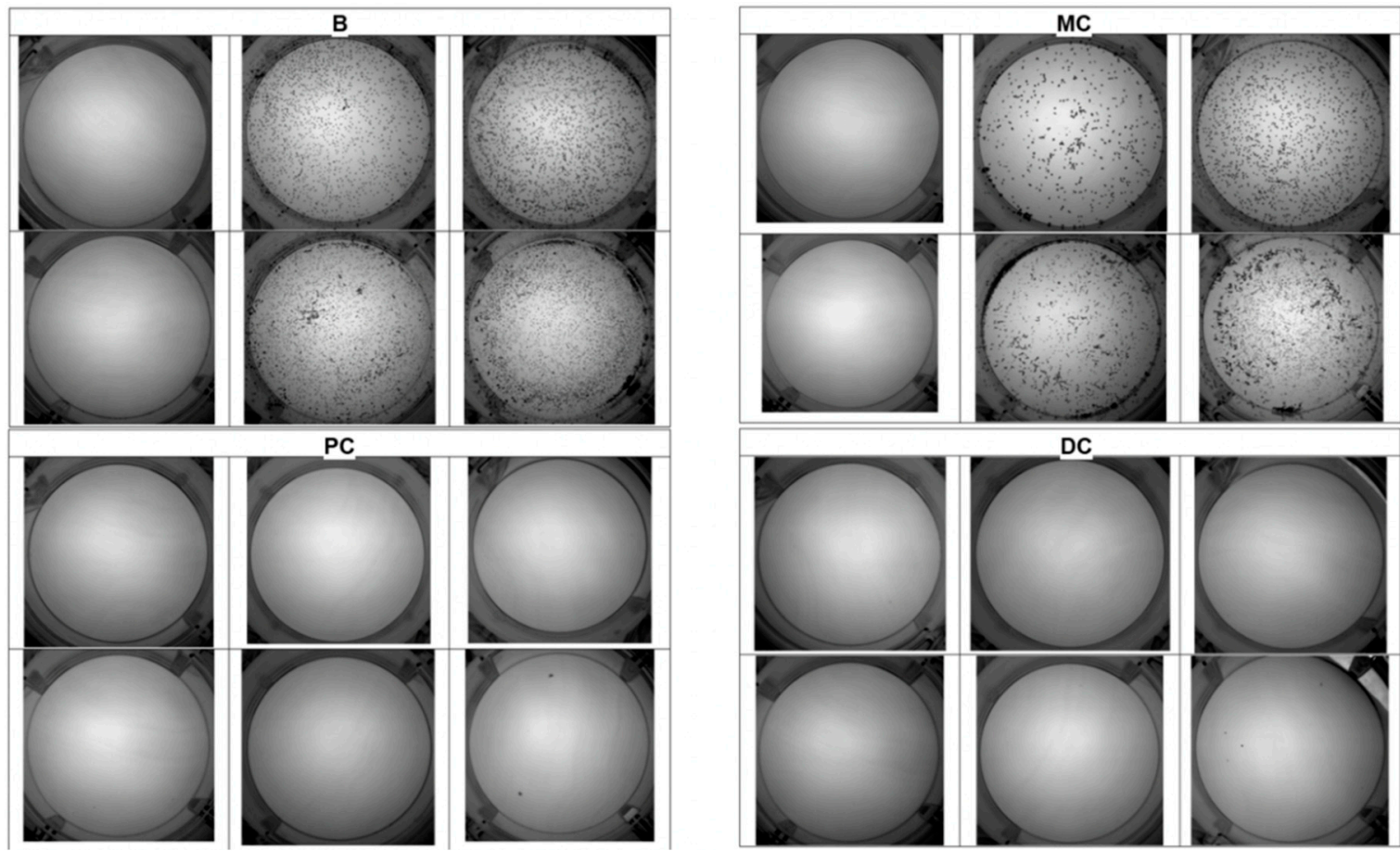

Figure 3. Representative UAC test results of one volunteer at baseline (B) and after consumption of milk chocolate (MC), chocolate powder (PC), and dark chocolate (DC). Uric acid crystallization was greatly reduced following consumption of chocolate powder or dark chocolate. 


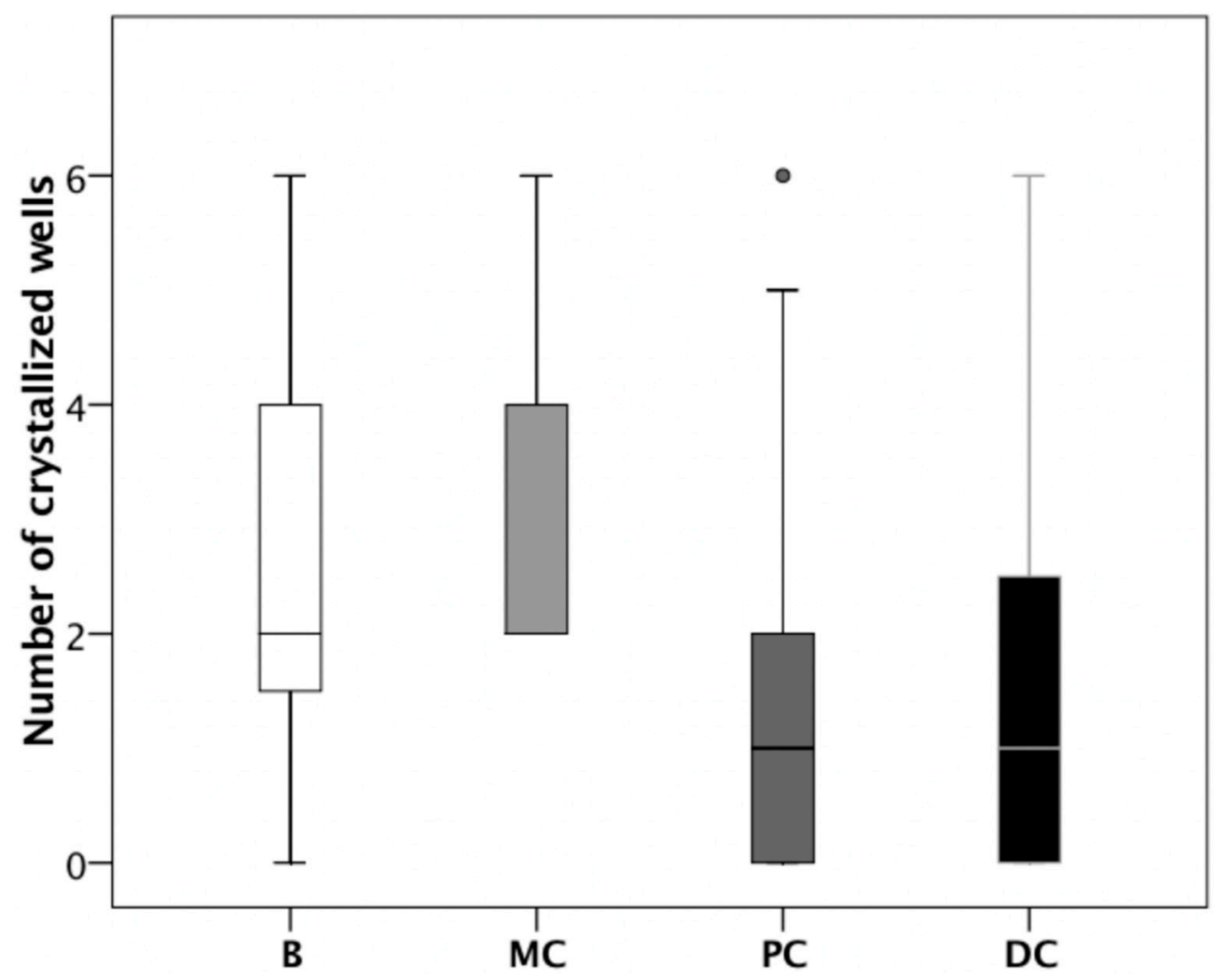

Figure 4. UAC test results at baseline (B) and after consumption of milk chocolate (MC), chocolate powder (PC), and dark chocolate (DC). Samples were compared using the Wilcoxon signed-rank test. Boxplots show the median (inner horizontal line), interquartile range (box), 95\% confidence interval (vertical lines), and outlier (circle).

\section{Discussion}

Uric acid renal lithiasis affects many individuals, and stone removal does not resolve the underlying pathological conditions. Thus, if the metabolic alterations responsible for stone formation are not corrected, there is a risk of future calculi [27]. As with other substances that precipitate in urine, the driving force is the supersaturation of a solute, so one might naively think that simply reducing supersaturation will solve the problem. Nevertheless, there are situations in which this is difficult to achieve, or requires great effort and willpower by the patient. For example, patients with metabolic syndrome have high urinary uric acid concentrations, and a urinary $\mathrm{pH}$ below 5.5, making them especially predisposed for uric acid kidney stones [28]. The current treatments thus require modification of the diet, with reduced consumption of purine-containing foods, and administration of urinary alkalinizers or xanthine oxidase inhibitors to reduce uric acid supersaturation. High patient compliance is necessary. However, pharmacological treatments can lead to certain long-term adverse effects, and patient adherence can be difficult. Moreover, the chronic consumption of alkalinizers can increase the urinary $\mathrm{pH}$ to above 6.2 , and this can favor phosphatic lithiasis [29]. Therefore, alternative treatments are needed for uric acid renal lithiasis.

One possible strategy is the use of crystallization inhibitors. These inhibitors must be safe, easily administered, absorbed through the gastrointestinal tract, and mostly eliminated in the urine, to achieve clinically effective concentrations. For uric acid renal lithiasis, no medically applicable substance had these properties, until the recent findings of the effects of theobromine [19]. Our results indicate that theobromine meets all the necessary requirements for treatment of uric acid stones. In particular, consumption of cocoa-derived products (milk chocolate, chocolate powder, and dark chocolate), which contain different amounts of theobromine, led to increased excretion and concentration of urinary theobromine (Figure 2), and this increase was greater for chocolate powder 
and dark chocolate than milk chocolate, which has a lower theobromine content. Moreover, the urinary concentrations of theobromine that we achieved were similar to those that inhibited crystallization in vitro [19].

To determine whether the presence of urinary theobromine prevents the formation of uric acid crystals, we performed UAC tests for urine samples collected at baseline (basal conditions) and after the consumption of different cocoa-derived products. The UAC test was designed so that in basal conditions crystallization of uric acid would occur in at least one of the wells when incubated at room temperature for $24 \mathrm{~h}$ (Figure 1), since in the absence of crystallization, the inhibitory effects are not manifested. In particular, each sample was subjected to different levels of acidification (by the addition of $\mathrm{HCl}$ ) and/or an increase of uric acid (by addition of a uric acid solution), so that the uric acid concentration was $150 \mathrm{mg} / \mathrm{L}$ higher (Figure 1). Thus, in one of the wells, an aliquot of the urine to be evaluated was introduced without any type of additive. It is evident that crystallization of uric acid depends on the $\mathrm{pH}$ and uric acid concentration of this urine and, as above commented, without uric acid crystallization it is not possible to evaluate the inhibitory effects of theobromine. For this reason aliquots of the same sample were added into two wells, in which the $\mathrm{pH}$ was decreased by the addition of two different amounts of $\mathrm{HCl}$. Although the $\mathrm{pH}$ values reached were much lower than the physiological values $(4.7 \pm 0.1$ and $2.8 \pm 0.3)$, they favored uric acid crystallization and allowed us to evaluate whether the increase in inhibitor concentration (theobromine) manifested inhibitory effects, since the urine of the same individual was compared before and after the intake of this substance. It is also possible that due to the low concentrations of uric acid in the native urine, its crystallization will not occur. For this reason, another aliquot of the sample was added into a well in which a supplement of uric acid $(0.75 \mathrm{mg})$ was added. Finally, to ensure that at least one well in which uric acid crystallization occurs was available, two wells with sample aliquots were added with the two $\mathrm{HCl}$ supplements already used together with the addition of $0.75 \mathrm{mg}$ of uric acid. In this way, we ensured that we could assess the majority of situations if an increase in the concentration of urinary theobromine for a given individual increases the capacity of inhibition of uric acid in its urine.

Interestingly, only 2 of the 20 healthy volunteers presented with uric acid crystals in untreated urine, indicating that $90 \%$ of them had no risk of uric acid crystallization.

The UAC test value of each sample ranged from 0 to 6, based on the number of wells with visible uric acid crystals (Figure 3). We also used other methods to assess the UAC test, such as an estimation of the percentage area of the crystals relative to the total area of the well, but this was very time consuming and did not improve our estimates of risk. We ultimately chose the simplest methodology.

Our UAC test results indicated that a greater concentration of theobromine reduced the risk of uric acid crystallization (Figure 4). In particular, the consumption of chocolate powder and dark chocolate both clearly decreased uric acid crystallization, although milk chocolate did not have a significant effect. This is consistent with the lower content of theobromine in milk chocolate and the lower urinary theobromine concentration of individuals following consumption of milk chocolate.

Although our study is the first evidence of the in vivo effects of theobromine as an inhibitor of the crystallization of uric acid, there were several limitations. In particular, we only examined 20 volunteers, all of whom were healthy non-stone formers, which was reason why uric acid did not crystallize in their urine unless uric acid was added or the sample was acidified. Thus our findings may have limited extrapolation. Another limitation is that urine composition was not the same in the four phases since it is affected by the diet, which was only controlled during the $12 \mathrm{~h}$ prior to the collection of samples. Finally, the theobromine sources were cocoa derived products, but the administration of theobromine extracts would be more appropriate, as they would avoid an increase of oxalate urinary concentration in stone-formers.

\section{Conclusions}

Our results indicated that an increased concentration of urinary theobromine reduced the risk of uric acid crystallization in urine. The consumption of moderate amounts of chocolate increased 
the urinary concentration of theobromine, and this increase depended on the type of chocolate consumed. Considering that chocolate also contains large amounts of sugar and oxalate, it may be more appropriate to administer theobromine supplements, especially for individuals with metabolic syndrome or other pathologies associated with uric acid stones. Further studies of patients with uric acid stones are necessary to prove the effectiveness of theobromine treatment.

Author Contributions: Conceptualization, A.C.-B. and F.G.; investigation, A.C.-B., F.G., P.C. and A.R.; methodology, A.C.-B., F.G., P.C. and R.M.P.; supervision, A.C.-B. and F.G.; writing-original draft, A.C.-B. and F.G.; writing-review and editing, A.C.-B. and F.G.

Funding: This research received no external funding.

Conflicts of Interest: The authors declare no conflicts of interest.

\section{References}

1. Ramello, A.; Vitale, C.; Marangella, M. Epidemiology of nephrolithiasis. J. Nephrol. 2000, 13, S65-S70.

2. Brikowski, T.H.; Lotan, Y.; Pearle, M.S. Climate-related increase in the prevalence of urolithiasis in the United States. Proc. Natl. Acad. Sci. USA 2008, 105, 9841-9846. [CrossRef] [PubMed]

3. Grases, F.; Costa-Bauzá, A.; Ramis, M.; Montesinos, V.; Conte, A. Simple classification of renal calculi closely related to their micromorphology and etiology. Clin. Chim. Acta 2002, 322, 29-36. [CrossRef]

4. Mandel, N.S.; Mandel, G.S. Urinary tract stone disease in the United States veteran population. I. Geographical frequency of occurrence. J. Urol. 1989, 142, 1513-1515. [CrossRef]

5. Mandel, N.S.; Mandel, G.S. Urinary tract stone disease in the United States veteran population. II. Geographical analysis of variations in composition. J. Urol. 1989, 142, 1516-1521. [CrossRef]

6. Gault, M.H.; Chafe, L. Relationship of frequency, age, sex, stone weight and composition in 15,624 stones: Comparison of resutls for 1980 to 1983 and 1995 to 1998. J. Urol. 2000, 164, 302-307. [CrossRef]

7. Costa-Bauzá, A.; Ramis, M.; Montesinos, V.; Grases, F.; Conte, A.; Pizá, P.; Pieras, E.; Grases, F. Type of renal calculi: Variation with age and sex. World J. Urol. 2007, 25, 415-421. [CrossRef] [PubMed]

8. Daudon, M.; Traxer, O.; Conort, P.; Lacour, B.; Jungers, P. Type 2 diabetes increases the risk for uric acid stones. J. Am. Soc. Nephrol. 2006, 17, 2026-2033. [CrossRef] [PubMed]

9. Trinchieri, A.; Montanari, E. Prevalence of renal uric acid stones in the adult. Urolithiasis 2017, 45, 553-562. [CrossRef] [PubMed]

10. Hesse, A.; Brandle, E.; Wilbert, D.; Köhrmann, K.U.; Alken, P. Study on the prevalence and incidence of urolithiasis in Germany comparing the years 1979 vs. 2000. Eur. Urol. 2003, 44, 709-713. [CrossRef]

11. Grases, F.; Costa-Bauzá, A.; Ramis, M.; Montesinos, V.; Conte, A. Recurrence of renal lithiasis. Scand. J. Urol. Nephrol. 2003, 37, 482-486. [CrossRef] [PubMed]

12. Ferraro, P.M.; Curhan, G.C.; D'Addessi, A.; Gambaro, G. Risk of recurrence of idiopathic calcium kidney stones: Analysis of data from the literature. J. Nephrol. 2017, 30, 227-233. [CrossRef] [PubMed]

13. Grases, F.; Villacampa, A.I.; Costa-Bauzá, A.; Söhnel, O. Uric acid calculi: Types, etiology and mechanisms of formation. Clin. Chim. Acta 2000, 302, 89-104. [CrossRef]

14. Sakhaee, K.; Adams-Huet, B.; Moe, O.W.; Pak, C.Y. Pathophysiologic basis for normouricosuric uric acid nephrolithiasis. Kidney Int. 2002, 62, 971-979. [CrossRef] [PubMed]

15. Ferrari, P.; Bonny, O. Diagnosis and prevention of uric acid stones. Ther. Umsch. 2004, 61, 571-574. [CrossRef] [PubMed]

16. Hess, B.; Jaeger, P. Physiopathology, etiology and medical treatment of non-calcium lithiasis. Rev. Prat. 1991, 41, 2037-2042. [PubMed]

17. Heilberg, I.P. Treatment of patients with uric acid stones. Urolithiasis 2016, 44, 57-63. [CrossRef] [PubMed]

18. Ngo, T.C.; Assimos, D.G. Uric acid nephrolithiasis: Recent progress and future directions. Rev. Urol. 2007, 9, 17-27. [PubMed]

19. Grases, F.; Rodriguez, A.; Costa-Bauza, A. Theobromine inhibits uric acid crystallization. A potential application in the treatment of uric acid nephrolithiasis. PLoS ONE 2014, 9, e111184. [CrossRef] [PubMed] 
20. Ptolemy, A.S.; Tzioumis, E.; Thomke, A.; Rifai, S.; Kellogg, M. Quantification of theobromine and caffeine in saliva, plasma and urine via liquid chromatography-tandem mass spectrometry: A single analytical protocol applicable to cocoa intervention studies. J. Chromatogr. B Anal. Technol. Biomed. Life Sci. 2010, 878, 409-416. [CrossRef] [PubMed]

21. Rodriguez, A.; Costa-Bauzá, A.; Saez-Torres, C.; Rodrigo, D.; Grases, F. HPLC method for urinary theobromine determination: Effect of consumption of cocoa products on theobromine urinary excretion in children. Clin. Biochem. 2015, 48, 1138-1143. [CrossRef] [PubMed]

22. Craig, W.J.; Nguyen, T.T. Caffeine and theobromine levels in cocoa and carob products. J. Food Sci. 1984, 49, 302-303. [CrossRef]

23. Lelo, A.; Birkett, D.J.; Robson, R.A.; Miners, J.O. Comparative pharmacokinetics of caffeine and its primary demethylated metabolites paraxanthine, theobromine and theophylline in man. Br. J. Clin. Pharmacol. 1986, 22, 177-182. [CrossRef] [PubMed]

24. Tarka, S.M.; Arnaud, M.J.; Kvorchik, B.H.; Vesell, E.S. Theobromine kinetics and metabolic disposition. Clin. Pharmacol. Ther. 1983, 34, 546-555. [CrossRef] [PubMed]

25. Tang-Liu, D.S.; Williams, R.L.; Riegelman, S. Disposition of caffeine and its metabolites in man. J. Pharm. Exp. Ther. 1983, 224, 180-185.

26. Marshall, R.W.; Robertson, W.G. Nomograms for the estimation of the saturation of urine with calcium oxalate, calcium phosphate, magnesium ammonium phosphate, uric acid, sodium acid urate, ammonium acid urate and cystine. Clin. Chim. Acta 1976, 72, 253-260. [CrossRef]

27. Fink, H.A.; Wilt, T.J.; Eidman, K.E.; Garimella, P.S.; MacDonald, R.; Rutks, I.R.; Brasure, M.; Kane, R.L.; Ouellette, J.; Monga, M. Medical management to prevent recurrent nephrolithiasis in adults: A systematic review for an American College of Physicians Clinical Guideline. Ann. Intern. Med. 2013, 158, 535-543. [CrossRef] [PubMed]

28. Spatola, L.; Ferraro, P.M.; Gambaro, G.; Badalamenti, S.; Dauriz, M. Metabolic syndrome and uric acid nephrolithiasis: Insulin resistance in focus. Metabolism 2018, 83, 225-233. [CrossRef] [PubMed]

29. Xu, H.; Zisman, A.L.; Coe, F.L.; Worcester, E.M. Kidney stones: An update on current pharmacological management and future directions. Expert Opin. Pharmacother. 2013, 14, 435-447. [CrossRef] [PubMed]

(C) 2018 by the authors. Licensee MDPI, Basel, Switzerland. This article is an open access article distributed under the terms and conditions of the Creative Commons Attribution (CC BY) license (http:/ / creativecommons.org/licenses/by/4.0/). 